\title{
Testing the Noticing Function of the Output Hypothesis
}

\author{
Sumayyah Qaed Alsulami ${ }^{1}$ \\ ${ }^{1}$ English Language Institute, King Abdul Aziz University, Saudi Arabia \\ Correspondence: Sumayyah Qaed Alsulami, English Language Institute, King Abdul Aziz University, Saudi \\ Arabia. E-mail: somayyah81@gmail.com
}

Received: October 3, 2015 Accepted: January 12, 2016 Online Published: January 14, 2016

doi: 10.5539/elt.v9n2p136 URL: http://dx.doi.org/10.5539/elt.v9n2p136

\begin{abstract}
In spite of Krashen's (1985) claims that the only way to acquire a second language is through non-stressful comprehensible input, Swain $(1995,1998,2005)$ and others propose that the production of language (speaking or writing), under certain circumstances, is a significant part of the second-language acquisition process. Swain also states that there are three functions of output, and one of these is the noticing or triggering function, in which through producing output, learners become aware of their linguistic knowledge. This study examines the role and effectiveness of output - in particular, the noticing function of language output - in developing the writing skills of an English as a Foreign Language (EFL) student from Saudi Arabia. The notice function enables the student to identify lexis and grammar problems in his writing. Data collection for the study was conducted in three stages: In Stage 1 the participant, who studies English at Latrobe Language Centre in Level 4A, wrote three paragraphs in response to illustrated questions. In Stage 2, the participant compared his original writing to model paragraph feedback tools. In Stage 3, the student rewrote his original paragraphs based on what he noticed in Stages 1 and 2. This methodology demonstrated the aspects of language that a second-language learner noticed while forming a paragraph on his own. It also illustrated what the participant noticed when he compared his writing to a model and what changes he made to his writing, as a result. It pushed the learner to create a modified output, leading to development of his writing skills in second-language acquisition.
\end{abstract}

Keywords: output hypothesis, noticing function, second language, acquisition

\section{Introduction}

In the early 1980s, the dominant hypothesis in the field of second-language acquisition was the input comprehensible hypothesis. Krashen (1985) insisted that the only way to acquire a second language was through exposure to sufficient input knowledge. In other words, input merely led to second language acquisition. However, research with French immersion students in Canada demonstrated that in spite of many years of comprehensible input in French, the second-language students showed less grammatical and syntactic proficiency than their native-speaking peers. Swain (1985) argued that one reason the learners made so many grammatical errors in their second language was because they produced less of the language. These findings lessened the validity of the input hypothesis.

This study sets out to prove the validity of the output hypothesis and the importance of using a target language as part of the language-acquisition process. It focuses on improvements made to the second-language writing skills of a learner from Saudi Arabia, where educators pay more attention to reading and listening (input). The study also emphasizes the noticing/triggering function of the output hypothesis and how it can assist learners in improving their writing. The report is divided into six sections. The first section provides a case study that introduces the research participant and his second-language learning experience. The next section outlines the linguistic aspects, or the lexical and grammatical features, discussed in this study and explains how the study was conducted. The third section is about the theoretical framework of the output hypothesis, reflecting the available literature. The next section outlines the findings of the study, based on the data contained in the language sample. The fifth section reviews the literature discussed in the third section, this time in light of the study's findings. The last section, then, provides conclusions of the main points in the report.

\section{Case Study}

The participant in this study is a 30-year-old male from Saudi Arabia, and his first language is Arabic. He started learning English as foreign language, like other students in his country, when he was in grade seven of 
intermediate school and 13 years old. His only experience learning English language was in a classroom setting, and the focus of his education was on input (i.e., listening and reading) more than any other skill (i.e., writing and speaking). The participant's only motivation was to get high marks and pass the course. His English teachers were non-native speakers with only Bachelor's degrees in English and no courses in teaching methods, and there were no resources for studying the language except for student and activity books. Once the participant finished secondary school, he never studied or used English in his life or at school, taking a nine-year break from his English learning. As a result, he forgot most of what he had learned in his modest English experience.

When the participant came to Australia in February 2011, he started at level 1 at the Language Centre in Latrobe University. He is now at level 4. The Language Centre focuses on the four skills of listening, reading, speaking, and writing. The teachers are native speakers, and students have many resources at their disposal, such as a library, computer labs, and activity classes for discussions of recent issues. In this setting, the participant realizes the importance of learning English, so he is motivated and interested to learn, not only so he may do a Master's degree in law but so that he may communicate and make relationships with people in Australia. In the past, he had no need to speak English for any reason - not even for his university studies in Saudi Arabia - but now, in Australia, the participant needs to use English everywhere, from the Language Centre to stores, coffee shops, and the hospital. The participant can have a conversation with his wife and daughter in English and can discuss topics in his class about learning, the environment, and current events. He also understands the general points when he watches movies or programs.

The participant is not satisfied with his language competence, however, because he faces some difficulties with his writing and finds that he always thinks in his first language and has to translate his ideas to English. Moreover, he says he does not like to revise anything he has written. He always repeats the same errors. Thus, the participant was chosen for this study because of his exposure to comprehensible input but his struggles to change his writing.

\section{Language Feature}

This study emphasized the linguistic features of English: grammar and lexis. The writing task for this study was designed to give the participant the opportunity to observe the linguistic errors he made in writing paragraphs in response to illustrated questions (Stage 1) and to point out gaps between his interlanguage writing and target writing based on a comparison of his paragraphs with model paragraphs on the same topics (Stage 2). The study also looked at how the participant rewrote his original paragraphs based on what he noticed about his linguistic errors and the linguistic features of the model paragraphs (Stage 3). The participant wrote three paragraphs in order to show more problems and because there is only one participant in the study. The questions posed by the study were:

1) What language features did the participant notice while writing the three paragraphs in his own?

2) What did the participant notice when he compared his original texts to the three models?

3) What were the impacts of the language features that the participant noticed in Stage 1 and Stage 2 on his rewriting in the last stage?

\section{Methodology}

The second-language learner (the participant) was asked to write a paragraph in response to a question with a picture. He was asked to answer three different questions by following the same stages. The first question asked the participant to describe the water cycle, the second asked how a rainbow gets its color, and the last question asked about the effects of passive smoking. The instructions for the task were given in Arabic, and the participant was allowed to take notes in Arabic. In Stage 1 of the writing task, the participant was given two sheets of paper and the first question. He was asked to write an answer to the question in paragraph form on the first sheet. Then he was asked to use the second sheet to take notes on whatever problems and difficulties he faced when writing his paragraph on the first sheet. Instructions for taking notes were given to the participant orally. He was encouraged to write, for example, "I do not know how to write X" or "I do not know the past tense of X." This stage took about 10 to 15 minutes. After that, the second sheet was collected, and the participant was allowed to keep the first sheet and the question for the next phase.

In Stage 2 of the study, which immediately followed the first stage, the participant was given a third sheet of paper and a model paragraph for the same question. He was asked to write points on things he noticed when comparing his original text to the model paragraph. This part of the task took about 10 to 12 minutes, and then the model text and third sheet were collected. The student was told to keep his original text and the question for the last stage, in which he was given a fourth sheet of paper and asked to rewrite his original text. This rewriting 
took about 10 to 15 minutes. Then all the sheets and the question were collected. This method was repeated two more times in order to answer the three different questions in the same way.

\section{Theoretical Framework}

Since Swain (1985) proposed the output hypothesis, she has explored more about this hypothesis and identified three roles of output in second-language acquisition. First, she says output provides a hypothesis-testing function. In other words, producing output is a significant way for a learner to test hypotheses about the target language. The learner can test his interlanguage comprehension and the accuracy of his linguistic formation against feedback received from interlocutors. Second, Swain (1995) says output has a metalinguistic function. The learner's output provides this metalinguistic function when he reflects upon his own target use, and that enables him to internalize linguistic knowledge. This emphasis on language may intensify the learner's awareness of forms, rules, and form-function if the context in which he produces this language is genuine and communicative. Finally, Swain (1995) says output can also provide a noticing/triggering function:

"In producing the target language (vocally or subvocally), learners may notice a gap between what they want to say and what they can say, leading them to recognize what they do not know, or know only partially, about the target language. In other words, under some circumstances, the activity of producing the target language may prompt second language learners to consciously recognize some of their linguistic problems; it may bring to their attention something they need to discover about their L2" (pp. 125-126).

Many studies have been conducted to examine the testing-hypothesis and metalinguistic functions. Some studies on the hypothesis-testing function (Pica, Holliday, Lewis \& Morgenthaler, 1989; Nobuyoshi \& Ellis, 1993), for example, have demonstrated that forcing learners to produce adequate and comprehensible output may have a positive, long-term effect, usually enabling the learners to improve their output. Other studies on metalinguistic function (Donato, 1994; Swain, 1995) have also shown that producing the target language and depending on it to generate meaning have great effects on the language-learning processes.

There have been few studies conducted, however, to examine the third function of output: the noticing/triggering function. One of these studies, conducted by Swain and Lapkin (1995), found that output does not merely indicate the noticing of problems in a second-language learner's interlanguage knowledge, but also motivates language acquisition by actuating various internal processes conducted in second-language acquisition. In other words, as Swain and Lapkin reported, students noticed their linguistic problems consciously. Shahadeh (2002) says that some researchers have emphasized creating modified output, but more researches are required to show how generating output can facilitate acquisition. Izumi et al. (1999) investigated the positive effect of output on noticing and second-language acquisition.

In this noticing research, the focus is on different linguistic aspects. Wajnryb (1990) proposes that "dictogloss" (dictation task) is a process which encourages learners to think deeply about their own output. He also points out that students tend to observe more the grammatical accuracy. In addition, Kowal and Swain (1994) argue that $70 \%$ of the language episodes generated dealt with accuracy too. While Williams (2001) reported that $80 \%$ of all the language episodes were lexical. Furthermore, Mackey et al. (2001) point out that the learners in their study who were learning English as a foreign language thought mainly about lexis. Swain and Lapkin (1995) pointed out in their study of 18 students that in the editing stage about $50 \%$ of language episodes were lexical.

Feedback on writing gives a learner opportunities to devote more attention to form and help him in the comparison between his own writing and the models to produce a modified output (Sachs \& Polio, 2007). There are numerous types of writing feedback. One is an error-correction form. This type of feedback, though, has limited effectiveness. Truscott (1996) argues, for example, that the error-correction form should no longer be used because it does not push learners to write but leads them to prefer to produce fewer errors by taking fewer risks. Another type of feedback is reformulation, which is a native speaker's rewriting of what the learner produced. Modeling feedback is a third type of feedback and the one used in this study. It also involves the use of a text that is written by a native speaker, but the text is original and not a reformulation of a learner's writing. Both the reformulation and modeling types of feedback share many advantages. They provide learners with rich texts of words and structure, especially for EFL learners who do are not as exposed to the forms that native speakers have (Manchon, 2009).

This paper outlines a study that follows previous studies and tries to demonstrate which language features are noticed by an English learner with an Arabic background. This study also focuses on how the learner solves problems in his language and to what extent this facilitates second language acquisition. 


\section{Findings}

In Stage 1 of the study, the participant wrote five notes about the problems and gaps he found while writing a paragraph about the water cycle. First, he noted that he did not know how to write the verb "evaporate" and instead wrote "go to up," though he knew it was not the correct verb. Second, he noticed that he did not know the verb "condense," so he just ignored this stage of the water cycle. Third, the participant mentioned that he did not know the meaning of the phenomena "water cycle." Then, he admitted that he wrote "water course" as an alternative phrase, though he knew that there was a better expression he did not know. The last note written by the participant said that he was not sure of the correct syntax for "the sun send it sunshine to the land." To sum, the learner noticed four lexical and one syntactic problem after he finished writing his original text.

In his next original paragraph, the learner wrote about how the rainbow gets its color. He subsequently said he noticed five points. The first was that he did not know this phenomenon in English, so he just wrote "the colors in the sky" to refer to the rainbow. He next noted that he did not know the verb "reflect" in English. He also was not sure of the spelling of the verb "appear." He wrote "appare." though he consciously knew that this spelling was not right. Then he indicated that he was not sure about putting the helping verb "is" after the subject "rain." Thus, he decided not to add "is" in the last sentence, writing: "after the rain stop." The participant's last point was that he was not sure if the word "land" in his last sentence was the appropriate word. Again in this paragraph, the participant noticed four lexical and one grammatical gap.

The participant's last was about passive smoking. After he finished writing this paragraph, he highlighted four points. The first point showed that he was not able to "lung cancer" in English. This led him to write only the word "cancer." He was also not sure of the spelling of the word "pollution," so this problem compelled him to write the verb of this word. Although he wrote the verb in the past participle tense, he was not sure of the spelling. He was also sure that his syntactic use of was bad, though he actually wrote it correctly. In this paragraph, the participant faced three lexical problems and one grammatical problem.

In all, in the three note-taking Stage 1s of the study, the participant wrote fourteen notes after writing his paragraphs. The majority of the errors he noticed (about 79\%) were lexical features, whereas the grammatical language features he noticed comprised about $21 \%$ of all the errors he noticed. This means that there was an overwhelming lexical aspect noticed in the first stage.

In Stage 2 of each writing task, once the participant had finished comparing his paragraphs to the model paragraphs, he wrote another set of notes on a third sheet of paper. In response to the first model paragraph, about the water cycle, he wrote that the verb "evaporate" was better for describing the water than "go up." He also noticed the word "vapor" was a good expression for the status of water in that stage. Moreover, he evaluated the use of two verbs - "condenses" and "forms" - that gave genuine meaning to the sentence. He also noted that the adjective "saturated" explained the clouds perfectly. His last note was grammatical, noting the good structure of the whole model paragraph.

In his notes on the model rainbow paragraph, everything the participant noticed while comparing his own writing to the model involved lexical features. The words that he listed included "droplets," "strike," "prism," and "reflect."

The participant wrote five notes when comparing his own paragraph about passive smoking and the model paragraph. His first note was that the verb "lead to" was the best way to link cause and effect. Then, he noticed the phrase "lung cancer," which he had been struggling before to remember. Next, he pointed out that the verb "create" was better for preceding "air pollution" than what he wrote in his first paragraph: "the air will be polluted." After that, the participant noticed the adjective "preventable" and mentioned that it was a good description of passive smoking. His last note was about how using the verb "expose" was better than the word he used it in his paragraph, "receive."

Stage 3 of each writing task was to rewrite the original three texts after noticing the gaps in the first drafts and comparing them to the models. The second draft of the participant's paragraph about the water cycle showed development in its lexical features. The participant provided some new words in the paragraph, such as "water cycle," "heat," "vapor," "condenses," and "release." Despite the lexical progress, though, the learner still had some unsolved grammatical problems. His rewrite of his paragraph about rainbows showed some correction in the grammar. For example, the participant changed the verbs "drop" and "send" by adding "s" to conjugate them for the singular nouns "water" and "sun." He also added a number of words that he had noticed in his comparison to the model, including "drop," "droplet," "reflect," and "rainbow." The third rewritten paragraph the one about passive smoking - saw some changes in its structure to correct some of its grammar. For instance, the participant changed the sentence "smoking cause a lot of effects" to "passive smoking may cause many 
effects." His use of "may" solved the grammatical error. In addition, the participant found a solution to one lexical problem in providing the exact phrase "lung cancer" instead of writing "cancer in the breath area," as he had in the original text of this paragraph. He also found a lexical solution in the correct spelling of the word "pollution." To sum, in this final stage of the writing task, the participant solved more lexical gaps than grammatical problems as a result of what he had noticed.

\section{Discussion}

The first question of this study was: What are the features of language that the participant notices while writing the three paragraphs in his own? The results demonstrated that the learner mainly noticed lexical problems and partly noticed grammatical gaps. This finding is to be expected because the majority of previous research (William, 2001; Machey et al., 2000; Swain \& Lapkin, 1995) has shown the same result. This result indicate that the participant's noticing feature is overwhelmingly focused on words. This may be because of the method of the noticing in this study, which was by taking notes, and may also be influenced by the participant's Arabic background. In Arabic language, words and spelling are the dominant aspects that the learner always should notice. Thus, this may affect the participant while doing this writing task.

The second question in this study was: What does the participant notice when he compares his original texts to the three models? The answer was the same as it was for the first question because the learner's noticing was influenced by the first stage of the study. He tried to solve the lexical gaps in his comparison of the two texts and thus looked for more words than any other features. The participant believes that having a rich repertoire of vocabulary is the best way to improve his writing. Therefore, this led him to notice lexis more than grammar. Moreover, the different structures of the learner's writings and the models contributed to his dismissal of the grammatical problems in his writing and his focus on the lexical problems instead.

The last question was: What are the consequences of Stage 1 and Stage 2 noticing on the rewriting stage? The answer was that the participant solved many of the problems that he had noticed in the first stage by finding solutions in the stage two. The majority of these solutions were related to lexical features, though, while a number of grammatical problems were not resolved. This may be due to the use of modeling feedback, which provided the student with numerous words, while the structure of the model was so different from the structure of the participant's text that it prevented him from noticing grammatical solutions. Overall, the participant in this study improved his modified output partly. This demonstrates the output hypothesis and how the noticing function, in particular, can facilitate learning a second language, despite some problems in need of solutions in the future.

\section{Conclusion}

In this study, the findings demonstrated the effective role of the noticing function in the output hypothesis of second-language acquisition. The participant was able to recognize some linguistic gaps in his English through the act of producing his writing, and this helped him pay more attention to the models in finding solutions to the problems. While this method of providing model texts can contribute to improving learners' writing by providing them with more words, however, some grammatical problems still need to be resolve. The use of notetaking as a feedback tool, for example, only facilitates resolution of lexical problems, so future researchers should consider choosing another method of feedback, such as reformulation. The Arabic background has an impact on lexical emphasizing, as well. The nature of this language forces its native speakers to pay more attention to words and lexis in general. In the end, this study found that the noticing function contributes to second language acquisition, in general, but that some linguistic problems still need to be solved in future research.

\section{References}

Donato, R. (1994). Collective scaffolding in second language learning. In J. P. Lantolf, \& G. Appel (Eds.), Vygotskian approaches to second language research (pp. 33-56). Norwood, NJ: Ablex.

Izumi, S., Bigelow, M., Fujiwara, M., \& Fearnow, S. (1999).Testing the output hypothesis: Effects of output on noticing and second language acquisition. Studies in Second Language Acquisition, 21(3), 421-452. http://dx.doi.org/10.1017/S0272263199003034

Kowal, M., \& Swain, M. (1997). From semantic to syntactic processing: How can we promote it in the immersion classroom? In R. K. Johnson, \& M. Swain (Eds.), Immersion education: International perspectives (pp. 284-309). Cambridge, UK: Cambridge University Press. http://dx.doi.org/10.1017/CBO9781139524667.022

Krashen, S. (1985). The input hypothesis. New York: Longman. 
Mackey, A., Gass, S., \& McDonough, K. (2000). How do learners perceive interactional feedback? Studies in Second Language Acquisition, 22(4), 471-497. http://dx.doi.org/10.1017/S0272263100004022

Manchon, R. M. (2009). Bristol, UK: Channel View Publications, Ltd.

Nobuyoshi, J., \& Ellis, R. (1993). Focused communication tasks and second language acquisition. ELT Journal, 47(3), 203-210. http://dx.doi.org/10.1093/elt/47.3.203

Pica, T., Holliday, L., Lewis, N., \& Morgenthaler, L. (1989). Comprehensible output as an outcome of linguistic demands on the learner. Studies in Second Language Acquisition, 11(1), 63-90. http://dx.doi.org/10.1017/S027226310000783X

Sachs, R., \& Polio, C. (2007). Learners' uses of two types of written feedback on a L2 writing revision task. Studies in Second Language Acquisition, 29(1), 67-100. http://dx.doi.org/10.1017/S0272263107070039

Shahadeh, A. (2002). Comprehensible output, from occurrence to acquisition: An agenda for acquisitional research. Language Learning, 52(3), 597-647. http://dx.doi.org/10.1111/1467-9922.00196

Swain, M. (1985). Communicative competence: Some roles of comprehensible input and comprehensible output in its development. In S. Gass, \& C. Madden (Eds.), Input in second language acquisition (pp. 235-253). New York: Newbury House Publishers.

Swain, M. (1993). The output hypothesis: Just speaking and writing aren't enough. The Canadian Modern Language Review, 50(1), 158-164.

Swain, M. (1995). Three functions of output in second language learning. In G. Cook, \& B. Seidhofer (Eds.), Principle and practice in applied linguistics (pp. 125-144). Oxford, UK: Oxford University Press.

Swain, M. (1998). Focus on form through conscious reflection. In C. Doughty, \& J. Williams (Eds.), Focus on form in classroom SLA (pp. 64-81). Cambridge, UK: Cambridge University Press.

Swain, M. (2005). The output hypothesis: Theory and research. In E. Hinkel (Ed.), Handbook of research in second language teaching and learning (pp. 471-483). London: Routledge.

Swain, M., \& Lapkin, S. (1995). Problems in output and the cognitive processes they generate: A step towards second language learning. Applied Linguistics, 16(3), 371-391. http://dx.doi.org/10.1093/applin/16.3.371

Truscott, J. (1996). The case against grammar correction in L2 writing classes. Language Learning, 46(20), 337-343. http://dx.doi.org/10.1111/j.1467-1770.1996.tb01238.x

Wajnryb, R. (1990). Grammar dictation. Oxford, UK: Oxford University Press.

Williams, J. (2001). Learner-generated attention to form. In R. Ellis (Ed.), Form-focused instruction and second language learning (pp. 303-346). Hoboken, NJ: Wiley-Blackwell. http://dx.doi.org/10.1111/j.1467-1770.2001.tb00020.x

\section{Copyrights}

Copyright for this article is retained by the author(s), with first publication rights granted to the journal.

This is an open-access article distributed under the terms and conditions of the Creative Commons Attribution license (http://creativecommons.org/licenses/by/3.0/). 